\title{
A proteção social na Nova Ordem Econômica Mundial
}

Recebido: 07.01.18 Aprovado: 01.11.18

André Simões*

Resumo: O presente trabalho tem como objetivo analisar as transformações na natureza dos sistemas de proteção social que produziram mudanças significativas na lógica das políticas sociais. A partir da utilização dos conceitos de Paradigma, Regime e Modos de Regulação, pretende-se mostrar que os sistemas de proteção social, embora continuem centrais ao funcionamento do capitalismo, adquiriram características que os diferenciam daqueles surgidos no pós-Segunda Guerra Mundial. Conclui-se que este novo paradigma de políticas impôs um novo olhar sobre as políticas sociais que se encontram cada vez mais associadas à estratégia do capital de promover a mercantilização da reprodução das condições de vida dos indivíduos. Revestidas por um discurso focado na promoção do bem-estar social, estas políticas se articulam às políticas econômicas na busca da promoção da expansão do processo de valorização do capital através da incorporação de segmentos vulneráveis da população ao mercado de consumo.

Palavras-chave: Proteção social. Políticas. Paradigma. Mercantilização. Condições de vida

\section{Social protection in the New World Economic Order}

Abstract: The present work aims to analyze the transformations in the nature of social protection systems that represented significant changes in the logic of social policies. Using the concepts of Paradigm, Accumulation Regimes and Modes of Regulation, it is intended to show that social protection systems, although remain central to the functioning of capitalism, have acquired characteristics that differentiate them from those that emerged in the Second World War. It is concluded that this new paradigm of policies imposed a new look on the social policies that are increasingly associated with the strategy of capital to promote the commodification of reproduction of individuals life conditions. Coherent in a discourse focused on the promotion of social welfare, these policies are articulated with economic policies in the pursuit of the expansion of the capital appreciation process through the incorporation of vulnerable segments of society into the consumer market.

Keywords: Social protection. Politics. Paradigm. Commodification. Life conditions.

\section{Introdução}

cada vez mais frequente a utilização do conceito de política social associado às diferentes modalidades de programas de transferência de renda que, voltados para a redução da pobreza, atuam corrigindo falhas de mercado. Uma

\author{
* André Simões \\ é pesquisador do \\ Instituto Brasileiro \\ de Geografia e \\ Estatística (IBGE), \\ Coordenação \\ de População e \\ Indicadores Sociais. \\ Doutor em Economia \\ pela Universidade \\ Federal do Rio de \\ Janeiro (UFRJ), \\ Rio de Janeiro, Rio \\ de Janeiro, Brasil. \\ Orcid: 0000- \\ 0001-5156-2175. \\ <andresimoes36@ \\ gmail.com>.
O IBGE não se responsabiliza por opiniões, informações, dados e conceitos contidos neste artigo, que são de exclusiva responsabilidade do autor.


definição de natureza estritamente econômica, que não leva em consideração o fato de as políticas sociais - como parte de sistemas de proteção social - serem inerentes e fundamentais ao capitalismo, pois garantem que algumas de suas contradições básicas não inviabilizem a reprodução das condições de vida da população. Embora com formatos que podem diferir segundo os distintos contextos histórico-institucionais que atuam ao longo de seu processo de implementação, as políticas sociais possuem natureza comum, ou seja, são produto do desenvolvimento das relações capitalistas de produção (Gough, 1979).

O período que se inicia no Pós-Segunda Guerra Mundial oferece um importante testemunho da centralidade que as referidas políticas passaram a ocupar no capitalismo. Cabe ressaltar que este período marcou de forma efetiva a consolidação de sistemas de proteção social pelos países europeus que, calcados num maior "equilíbrio" na relação capital/trabalho, permitiu a apropriação, por estes últimos, de importante fatia do produto nacional. Neste contexto, as políticas sociais adquiriram organicidade ao sistema, garantindo a desmercantilização da reprodução das condições de vida da população, o que significa, em outros termos, que a expansão dos mercados ocorreu sem romper com a organização política e social que Ihe conferia sustentabilidade (Polanyi, 2000). Este fato garantiu um crescimento com redistribuição ao longo de mais de 30 anos nos países europeus.

A crise deste modelo de desenvolvimento, a partir de final dos anos de 1970, marcou o início do processo de reestruturação das políticas sociais que, com a implantação de um novo paradigma de políticas, adquiriu novas feições. O avanço das ideias neoclássicas, no campo da economia, e da Terceira Via, no campo da política, conferiu nova funcionalidade aos sistemas de proteção social que, agora submetidos à lógica mercantil, passaram a atuar na expansão das relações de mercado, seja através do aumento da concessão de benefícios in cash, seja através da (re)mercantilização da provisão de serviços, como educação, saúde e habitação.

A incorporação das políticas sociais ao arcabouço de políticas neoclássicas é um fenômeno que remete ao final dos anos de 1980, quando, em virtude do aumento da deterioração das condições de vida da população, decorrente dos ajustes e da reestruturação das economias centrais e em desenvolvimento, agências multilaterais de desenvolvimento - como o Banco Mundial - começaram a avançar na elaboração de políticas pontuais e de baixo impacto orçamentário focalizadas em públicos vulneráveis (World Bank, 1990). Mas sua efetiva instrumentalização e articulação ao framework neoclássico ocorreu a partir dos anos de 1990, quando foram instituídos novos pilares conceituais, conferindo nova lógica de atuação às 
políticas sociais, que se voltaram para a ampliação da fronteira de valorização do capital através da incorporação ao mercado dos segmentos vulneráveis da população - seja através do aumento de sua participação no mercado de trabalho, seja pelo acesso deles a programas de transferência de renda (Lavinas, 2013; Lavinas \& Simões, 2015).

A análise do rompimento com a organicidade sistêmica que caracterizava as políticas sociais no Pós-Segunda Guerra Mundial e a decorrente instituição de um novo paradigma de políticas, onde elas foram instrumentalizadas e submetidas à lógica mercantil em constante expansão é o objetivo do presente trabalho. Pretende-se mostrar que, embora as políticas sociais atuais ainda sejam centrais ao desenvolvimento do capitalismo, sua função mercantil fere a natureza que Ihe confere existência, na medida em que não mais protegem os indivíduos contra as flutuações no mercado, mas, pelo contrário, atuam cada vez mais no sentido de viabilizar a reprodução de suas condições de vida unicamente através dele

- As evidências a esse argumento podem ser observadas no crescimento da provisão privada de serviços antes considerados desmercantilizados (como saúde e educação); do número de serviços oferecidos por empresas aos estratos mais pobres da população, como os micro seguros (planos de saúde, auxílio funeral, previdência privada etc.); o crédito ao consumo; o microcrédito (seja para o desenvolvimento de empreendedores, seja para garantia de acesso à educação superior); e os programas de transferência de renda de diferentes modalidades, que passam a ser considerados a principal via de promoção do acesso a direitos sociais - como os serviços de saúde, educação e moradia (Lavinas, 2013).

O trabalho está dividido em cinco partes, além desta introdução. A seção seguinte trará uma análise das principais características do modelo de proteção social surgido no período Pós-Segunda Guerra Mundial. Serão pontuadas as relações estabelecidas entre as políticas sociais e as políticas econômicas, bem como os fatores políticos e sociais que estiveram por trás do surgimento do referido modelo. Nesse sentido serão ressaltados aspectos referentes à coesão social, à cidadania política, à mobilização da classe trabalhadora etc., como forma de mostrar que as políticas sociais fazem parte da organização social do sistema capitalista e, como tal, evoluem em conjunto com as transformações da economia.

Na segunda parte, procurar-se-á analisar os fatores que estiveram na origem da crise econômica dos anos 1970 e seus impactos sobre os modelos de proteção social europeus. Será dada ênfase à ascensão do discurso neoliberal sobre a necessidade de redução do tamanho do Estado e desregulamentação da economia. 
Da mesma forma, serão expostas as críticas efetuadas em relação aos modelos de proteção social, bem como as tentativas de desmantelamento deles. Objetiva-se, com isso, mostrar que embora as políticas neoliberais tenham avançado inicialmente, seus efeitos sobre as estruturas econômicas e sociais - aumento do desemprego, queda da renda e da produtividade, aumento das desigualdades produziram reações das mesmas instituições políticas e sociais que se formaram no Pós-Segunda Guerra, obrigando os formuladores de políticas a incorporarem as políticas sociais ao seu arcabouço teórico através de uma reestruturação que redefiniu sua natureza e lógica de funcionamento em moldes diferentes ao que até então prevalecia.

Esta dinâmica está na origem do conteúdo da terceira parte do artigo, que se propõe a discutir algumas características deste novo formato de políticas sociais. A sua instrumentalização e subordinação às políticas voltadas à expansão das relações mercantis é fruto dos processos responsáveis pela instituição do novo paradigma de políticas, legitimando, com isso, um discurso em prol da eficiência e da responsabilização do indivíduo (Holzmann \& Jørgensen, 2000). Tal característica está na origem do surgimento de diferentes modalidades de programas de transferência de renda, das políticas de dinamização do mercado de trabalho e das novas formas de provisão de serviços que, respaldados pelo discurso das agências multilaterais de desenvolvimento, se tornaram importantes instrumentos de políticas sociais e uma das principais soluções do capital para amenizar suas históricas contradições.

Na quarta parte, é apresentada uma pequena análise das políticas sociais no governo do Novo Trabalhismo britânico. A escolha da Inglaterra se deve basicamente ao fato deste país ser um importante veículo de disseminação de novas ideias e de novas políticas para o mundo ocidental - herança do longo período de hegemonia econômica, política e de ideias (esta ainda forte) - além de figurar como importante "laboratório" de gestação e experimento do novo paradigma de políticas sociais, que vem se expandindo para outros países e se naturalizando como principal via de políticas no campo social.

Por fim, na quinta parte são tecidas algumas considerações sobre a formação deste novo paradigma de políticas e seus efeitos sobre as condições de vida da população. 


\section{A formação do modelo de desenvolvimento do Pós-Segunda Guerra: a efetiva centralização das políticas sociais}

O fim da Segunda Guerra Mundial marcou o início de um período de efetiva centralização das políticas sociais na estratégia de desenvolvimento dos países europeus. O crescimento tímido e vinculado às demandas específicas das legislações sociais, ao longo da primeira metade do século XX, ganhou velocidade no período posterior à guerra, simbolizando a consolidação de um modelo de desenvolvimento no qual o Estado desempenhava função fundamental no processo de reprodução das relações capitalistas de produção.

O Gráfico 1 mostra a evolução percentual das transferências sociais em relação ao Produto Interno Bruto (PIB) de alguns países da Organização para a Cooperação e Desenvolvimento Econômico (OCDE) entre 1910 e 1980. Todos os países analisados apresentaram crescimento expressivo de suas transferências sociais ao longo dos anos, com especial destaque para o período que se inicia em 1960, movimento que indica a generalização de um modelo cuja política social é peça-chave no processo de desenvolvimento. Cabe destacar que, enquanto a mediana das transferências sociais era de apenas 2,2\% do PIB nos países da OCDE em 1930, em 1980, chegou a $22,6 \%$. Países como Bélgica, Suécia, Noruega, Holanda e Alemanha contabilizaram, em 1980, transferências de mais de $25 \%$ do PIB, crescimento considerável quando

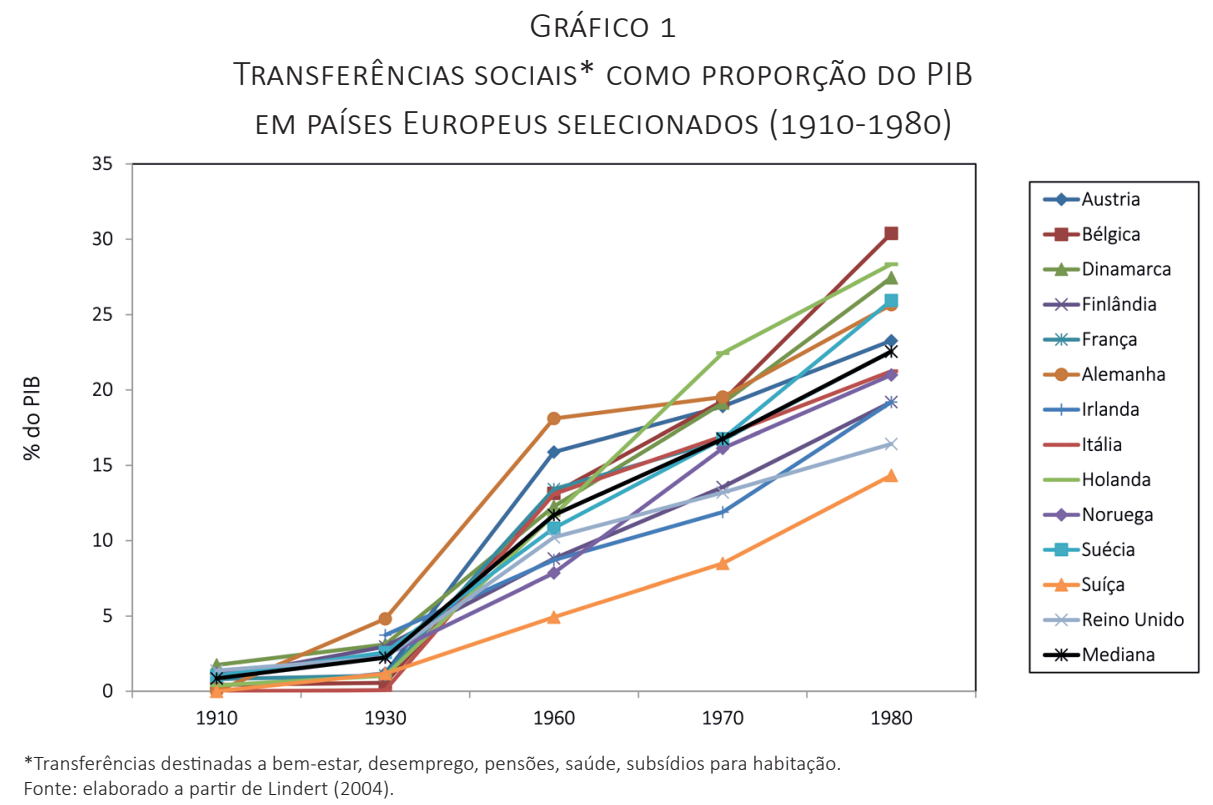


comparado com o período anterior a Segunda Guerra Mundial, quando esses percentuais não chegavam a $5 \%$ do PIB.

Mas quais foram os fatores que estiveram por trás do avanço das políticas sociais no Pós-Segunda Guerra? Em outras palavras, por que, no período que se seguiu à Primeira Guerra Mundial, não houve igual crescimento das legislações sociais, já que as demandas sociais eram altas, em virtude dos estragos provocados pelos bombardeios? A resposta para tal questão se encontra no fato de o período posterior à Segunda Guerra Mundial ter consolidado uma série de acontecimentos que vinham ganhando relevância ao longo da primeira metade do século XX. Cabe destacar, desta forma, o aprofundamento das relações capitalistas de produção, que passaram a demandar maior intervenção estatal como forma de garantir o processo de reprodução do sistema; o aumento da mobilização da classe trabaIhadora, que passou a reivindicar melhorias em suas condições de vida; e o avanço da constituição dos direitos sociais, como resposta à situação de vulnerabilidade que a população europeia estava sujeita, em virtude das guerras e das crises econômicas. Todos esses acontecimentos representaram, na verdade, uma resposta à fragilidade do modelo de desenvolvimento baseado unicamente nas forças de mercado - vigente no período entre guerras -, mostrando a necessidade de constituição de um novo modelo que tivesse o Estado como ator importante no processo de desenvolvimento e as políticas sociais como uma de suas estratégias de intervenção.

Nesse sentido, podem-se localizar os fatores que viabilizaram o desenvolvimento do

1. De acordo com Korpi (1985), o período PósSegunda Guerra foi acompanhado por um expressivo crescimento das lideranças de esquerda e socialdemocratas nos principais países europeus, o que se traduziu numa maior intervenção do Estado nas questões econômicas e sociais. Só para se ter uma ideia, entre 1946 e 1980 cerca de um terço das posições de comando desses países estavam em poder destes partidos. modelo Pós-Segunda Guerra Mundial em três campos analíticos, que estão fortemente articulados: o político, o social e o econômico. No campo político, destaca-se a ascensão de partidos de esquerda e de centro-esquerda, em especial os defensores da social-democracia ${ }^{1}$. O fim da guerra marcou também o enfraquecimento de uma série de movimentos conservadores de direita (muitos dos quais vinculados às ideais do nazismo), abrindo caminho para a chegada ao poder de movimentos vinculados às classes trabalhadoras e médias, com um discurso voltado não para o enfrentamento do capitalismo, mas sim por sua reformulação. Acreditava-se que o capitalismo poderia ser benéfico para a sociedade, desde que fosse controlado por instituições extramercado (Judt, 2008).

No campo social destaca-se a incorporação dos direitos sociais à cidadania que permitiu a superação de uma visão de sociedade centrada no indivíduo, cedendo espaço para o crescimento da ideia de coletividade e solidariedade entre a população. De acordo com Marshall (1967) e Barr (2004), as dificuldades enfrentadas pela população britânica nos tempos da guerra atingiram todas as classes sociais, produ- 
zindo um sentimento de solidariedade e união que se reverteram posteriormente na criação de uma série de legislações sociais voltadas para toda a população, independentemente de sua situação social ou laboral. É igualmente importante destacar a crescente mobilização da classe trabalhadora que, revestida pelo direito ao voto, se tornara cada vez mais fonte de pressão em prol da extensão dos direitos sociais para toda a população.

Por fim, no campo econômico, se destaca a implementação de políticas econômicas de base keynesianas que, em conjunto com a introdução de ferramentas de planejamento governamental ${ }^{2}$, passaram a refletir efetivamente a necessidade de substituição de um modelo econômico pautado pelas forças do mercado, por um novo modelo, onde o Estado assumiria papel central na promoção da eficiência econômica. Ao contrário do planejamento das economias centralizadas, que se encontravam sob o domínio da então União Soviética, e onde as relações econômicas eram determinadas pelo Estado, nos países do oeste europeu o planejamento tinha por objetivo corrigir as distorções no funcionamento do mercado, mediante a intervenção do Estado em questões econômicas e sociais.

Para Jessop $(1999,2002)$ este período é caracterizado pela formação de um regime fordista de acumulação que se baseia num ciclo virtuoso de produção em massa e consumo de massa, calcado num modelo macroeconômico de crescimento, que é sustentado, por sua vez, em uma estratégia expansionista, cujas principais características são: a elevação da produtividade, baseada nos ganhos de escala; o crescimento da renda, vinculada aos ganhos de produtividade; o crescimento da demanda, devido à elevação dos salários; o crescimento dos lucros, em virtude da plena utilização da capacidade produtiva; e o crescimento do investimento em máquinas e equipamentos, como forma a viabilizar a produção de massa (Jessop, 2002).

A sustentação institucional deste regime, por sua vez, ocorreu através de um modo de regulação cuja forma e função estrutural desempenhadas pelo Estado é denominada pelo autor de Keynesian welfare national State (KWNS). O termo keynesiano está relacionado à busca de lucratividade do capital, através da utilização da máxima capacidade produtiva da economia, que é auferida a partir da elaboração de políticas cíclicas pelo lado da demanda, políticas que tenham como objetivo alcançar o pleno emprego. Em segundo lugar, ele possui uma orientação para o bem-estar social (welfare), pois considera a força de trabalho como uma mercadoria fictícia, isto é, sua reprodução tem de ser realizada a partir de mecanismos extramercado. A política social, neste caso, não seria utilizada apenas para garantir a desmercantilização da força de trabalho, mas funcionaria igualmente como uma base sobre a qual as políticas econômicas keynesianas atuariam. Cabe ressaltar a importância
2. O planejamento econômico ganhou força através da implementação do Plano Marshall, iniciativa tomada pelo governo dos Estados Unidos que previa a concessão de empréstimos para a reconstrução dos países europeus afetados pela guerra. Como havia necessidade de gerir os recursos financeiros oriundos do plano, os países procuraram desenvolver uma série de instrumentos de planejamento que, por terem sido executados no âmbito da administração pública, contribuíram para o fortalecimento da presença do Estado nesses países (Judt, 2008). 
que a extensão dos direitos sociais assumiu neste processo, onde, através da ampliação dos benefícios sociais, permitiu a generalização das normas de consumo para além dos trabalhadores do sexo masculino, via criação de um salário família (family wage); além da promoção de formas de consumo coletivo favorável a dinâmica de crescimento fordista.

Em terceiro lugar, o tipo-ideal de Jessop (2002) tem como referência a escala nacional, já que as políticas econômicas e sociais são concebidas a partir de uma matriz que tem como base os Estados nacionais, a economia nacional, além de uma sociedade cuja cidadania é nacional (Jessop, 1999). Por fim, o KWNS tem uma conotação estatal, pois o Estado é o ator político central na implementação das políticas que irão corrigir as falhas de mercado, garantindo, com isso, crescimento econômico sustentado e coesão social. Nas palavras de Jessop (1999):

[...] the KWNS was statist in so far as state institutions (on different levels) were the chief supplement to market forces in securing the conditions for economic growth and social cohesion. It was the combination of market and state on different levels that prompted the use of the term "mixed economy" to describe the postwar system (classically, Shonfeld 1965). In addition to its role in facilitating and correcting the operation of market forces, the state also had a dominant role in shaping civil society and thus the identities held by its citizens (Jessop, 1999: 350, grifos nossos).

Os resultados alcançados pelo modelo de desenvolvimento podem ser vistos ao se compararem as informações sobre crescimento econômico e gastos sociais. Ficou claro, pelo Gráfico 1, que o período Pós-Segunda Guerra foi marcado por um substancial aumento das transferências sociais como proporção do PIB. Este crescimento da intervenção social do Estado foi acompanhado por um aumento expressivo do PIB dos países europeus que, entre 1950-1973, cresceu a uma taxa média anual de 4,6\%, percentual superior ao de apenas 1,8\% verificado no período 1913-1950 (Sigh, 2008). Além do crescimento do PIB, este período também foi marcado por um expressivo crescimento da produtividade da economia, o que significa, de acordo com o modelo descrito anteriormente, maiores salários para os trabalhadores, já que estes eram reajustados em função da barganha entre trabalhadores e empresários pela incorporação dos ganhos de produtividade. O Gráfico 2 ilustra bem este fato, ao mostrar que, entre 1870 e 2008, tanto os ganhos de produtividade quanto o crescimento do PIB per capita tiveram suas maiores taxas no período de 1950-1973.

A partir de meados da década de 1970, no entanto, começaram a surgir indícios de esgotamento do modelo, em virtude, principalmente, da redução dos lucros do 
GRÁFICO 2

MÉDIA DAS TAXAS MÉDIAS ANUAIS

DE CRESCIMENTO DO PIB PER CAPITA E

DA PRODUTIVIDADE* PARA UM CONJUNTO DE PAÍSES EUROPEUS

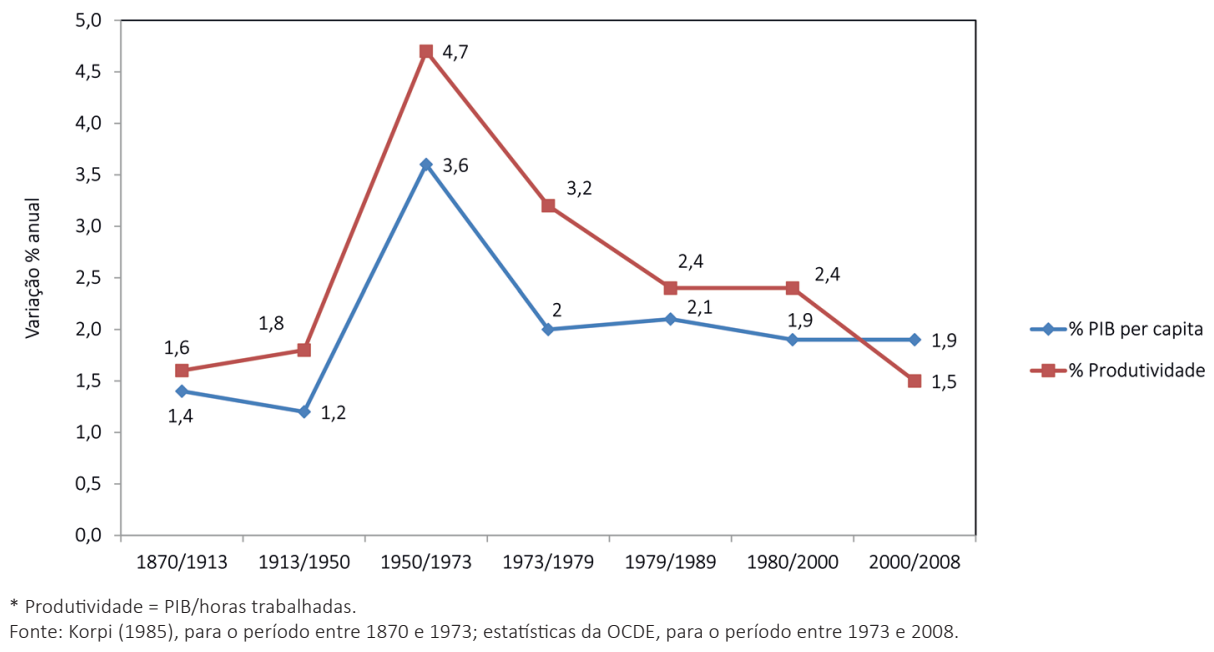

capital. Com o fortalecimento das ideias neoliberais, as críticas passaram a se voltar para a excessiva presença do Estado na economia, responsável, segundo essa corrente do pensamento econômico, pelos problemas de ineficiência alocativa das economias. Como um dos componentes estratégicos do modelo de desenvolvimento do pós-guerra, as políticas sociais também passaram a ser alvo de críticas, especialmente em função do seu crescente peso no orçamento dos países. A próxima seção explora este ponto com maior detalhamento, quando será dada ênfase às relações entre as transformações no capitalismo e às políticas sociais no período que começa em meados dos anos 1970.

\section{A crise no modelo de desenvolvimento do Pós-Segunda Guerra Mundial e seus efeitos sobre as políticas sociais}

A década de 1970 foi palco de inúmeras transformações na esfera econômica e política dos países europeus. Cabe destacar, no campo econômico, a emergência de uma crise que se manifestou no crescimento do endividamento dos países, com reflexos no aumento do desemprego, da inflação e na taxa de juros, além da queda dos níveis de investimento e da produção. Como resultado deste fenômeno, abriu-se caminho para o fortalecimento das críticas ao modelo de desenvolvimento do período Pós-Segunda Guerra, apropriadas, principalmente, pelos defensores das 
3. A abordagem de Hall (1990) parte do pressuposto de que as ideias possuem um papel fundamental na difusão e consolidação das políticas, sendo estas concebidas como aprendizado (policy learning). Nesse sentido, os formuladores de políticas atuam no âmbito de um conjunto de ideias que especificam não apenas os objetivos das políticas e os seus instrumentos de atuação, como ainda revelam a natureza dos problemas que propiciaram o desenvolvimento dessas ideias. A esta relação entre o contexto específico de desenvolvimento das ideias e sua difusão através das políticas, o autor chama de paradigma de política (policy paradigm). ideias neoliberais que passaram a apontar o elevado gasto público como o principal fator gerador da crise. De fato, como pontua Kornis (1994), a utilização do instrumental de política econômica desenvolvido no modelo do KWNS não estava surtindo o efeito desejável no combate à crise econômica, isto é, o incentivo à demanda agregada (via aumento da renda dos trabalhadores e dos gastos governamentais) não mais produzia o efeito multiplicador sobre a economia, com reflexos sobre o aumento no emprego, na produção e no investimento. Ao contrário, a utilização desse instrumental estava agravando ainda mais a situação financeira dos Estados europeus, o que é um indicativo de que as mudanças em curso no campo da economia política internacional estariam modificando a base social, econômica e política que dava sustentação ao modelo de desenvolvimento do Pós-Segunda Guerra.

Nesse sentido, é igualmente importante destacar as transformações no campo político, que foram fortemente influenciadas pelas mudanças na esfera econômica. Ganha destaque, desta forma, a ascensão ao poder de partidos conservadores que, munidos de discurso antiestatista, passaram a defender o desmantelamento do modelo de desenvolvimento do pós-guerra. O aumento do desemprego, a desarticulação dos sindicatos e a crescente perda da legitimidade conferida ao modelo de desenvolvimento ora em crise, criaram as bases para o fortalecimento destes partidos, que traziam como bandeira ideológica o discurso neoliberal, ou seja, afirmavam que a intervenção do Estado na economia produziria ineficiências alocativas. O Estado de bem-estar social, por representar uma das formas de intervenção estatal no mercado, além de consumir uma proporção expressiva dos gastos públicos, passou a ser o alvo central dos ataques destes partidos (Kornis, 1994).

Ao discutir as transformações no âmbito das políticas econômicas keynesianas no Reino Unido, Hall (1990) afirma que os processos que minaram sua efetividade no combate à crise dos anos 1970 pavimentaram o caminho para o florescimento das políticas econômicas monetaristas, o que, em sua visão, marcou a instituição de um novo paradigma de política econômica ${ }^{3}$. Este novo paradigma não se institucionalizou apenas através da introdução de novos instrumentos de política econômica, mas principalmente pelas mudanças nos objetivos a serem almejados pelas referidas políticas. No caso do Reino Unido, por exemplo, a busca pelo pleno emprego, que até então era o grande objetivo da política econômica do Pós-Segunda Guerra Mundial foi deixado de lado, cedendo espaço para as políticas de controle da inflação, meta atingida através da manutenção de altas taxas de desemprego, o que mostra a natureza radical do processo de instituição do novo paradigma. 
Para o referido autor, um novo paradigma de política se impõe na medida em que a natureza dos problemas a serem resolvidos se transforma, eliminando, dessa forma, o antigo paradigma, já que as ideias que alimentam a elaboração de suas políticas não são efetivas na resolução dos novos problemas. Adaptado do trabalho clássico de Kuhn (2010), o conceito de paradigmas tratado por Hall (1990) remete às transformações geradas pelas revoluções científicas, ocorridas em determinados períodos históricos, e que representaram mudanças no olhar sobre fenômenos científicos. Muda-se um paradigma e com ele o olhar sobre o mundo, levando a que os problemas tratados e os instrumentos utilizados sejam diferentes dos que prevaleciam no paradigma anterior(Kuhn, 2010).

Em um primeiro momento, este novo paradigma - ainda em processo de legitimação - conferia às políticas sociais não mais do que um papel residual, onde elas não deveriam ter impactos orçamentários significativos - uma aplicação literal do monetarismo. A crise dos anos 1970 evidenciou, para os adeptos desta corrente, os limites de um modelo baseado na forte intervenção estatal na economia, onde as políticas sociais produziriam ineficiências alocativas, já que não só consumiriam percentuais elevados do gasto público, mas também influiriam na determinação dos salários e nas relações entre oferta e demanda da economia. Nesse sentido, o fortalecimento do discurso neoliberal trazia em sua essência a elaboração de políticas que levassem à redução do peso dos Estados de bem-estar social no gasto público dos países - dentro de uma concepção diferente da que prevaleceu no período Pós-Segunda Guerra Mundial -, em que as políticas sociais adquiririam papel antagônico às políticas econômicas, sendo consideradas um custo econômico.

Grande parte das evidências empíricas mostrou, no entanto, que este novo paradigma em gestação apresentava contradições, isto é, a disseminação de novas ideias no campo da política econômica não encontrou o respaldo esperada na realidade concretamente vivida. Em outras palavras, mesmo estando no poder em uma série de países, os defensores e difusores das políticas monetaristas (ou neoliberais) não lograram suprimir, ou mesmo reduzir ao mínimo possível o Estado de bem-estar social (Pierson, 1996). Pelo contrário, o peso tanto das transferências sociais, quanto dos gastos governamentais continuou elevado nos países europeus. O Gráfico 3 ilustra bem este ponto, ao mostrar o crescimento tanto do consumo do governo quanto das transferências sociais em relação ao PIB, ao longo das décadas cujo domínio das políticas neoliberais é marcadamente acentuado. Só para se ter uma ideia, entre 1970 e 2010 o consumo governamental cresceu cerca de $20 \%$ e, entre 1970 e 2000, as transferências governamentais tiveram um incremento de quase $42 \%$. 
GRÁFICO 3

GASTOS GOVERNAMENTAIS COM CONSUMO*

E COM TRANSFERÊNCIAS SOCIAIS**, EM RELAÇÃO AO PIB.

MÉdIA DE ALGUNS PAÍSES EUROPEUS SELECIONADOS (1970/2010)

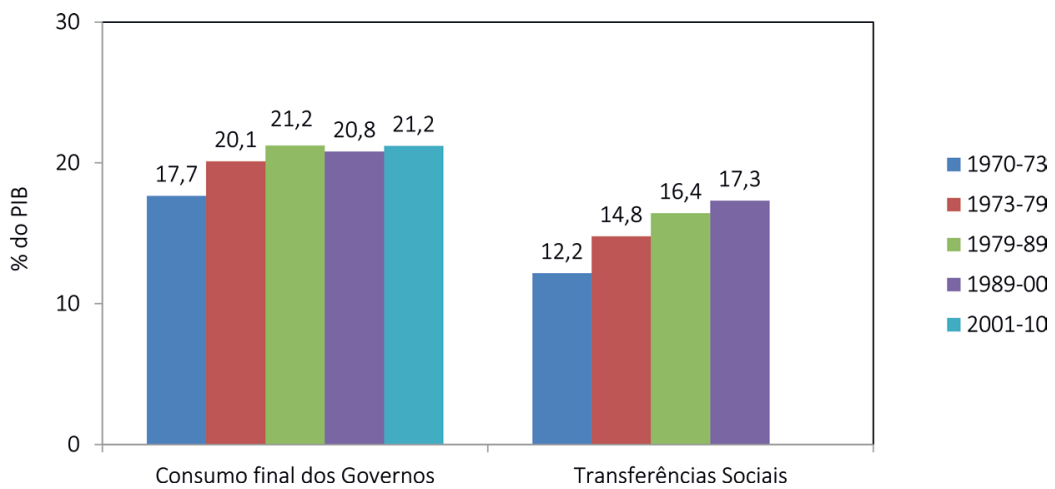

*Refere-se ao consumo de bens e serviços.

** Refere-se aos benefícios de seguridade social direcionados a doença, velhice, auxílio às famílias, subsídios para assistência social e benefícios para os trabalhadores pagos pelo governo.

Fonte: Estatísticas da OCDE. No caso das transferências sociais, considerou-se apenas o período 1970/2000.

Em outras palavras, a tentativa de instituição de um novo paradigma de política econômica (neoliberal stricto sensu) esbarrou nas evidências historicamente comprovadas de que o capitalismo necessita de proteção social para se reproduzir. Nesse sentido, governos nacionais, assim como agências multilaterais de desenvolvimento, mudaram de estratégia e passaram a incorporar as políticas sociais a este novo paradigma, conferindo-Ihe nova funcionalidade, que foi levada a cabo partir de um processo de reestruturação delas (World Bank, 1990; 1999). Esta nova articulação entre políticas econômicas e sociais, em um ambiente institucional marcado por transformações profundas no papel dos Estados Nacionais, pavimentou o caminho para a criação de um novo regime de acumulação do capital que, sustentado por um novo modo de regulação, intensificou a expansão das relações de mercado para todos os segmentos das sociedades capitalistas. As políticas sociais mantiveram sua centralidade nesse processo, mas foram redefinidas tanto no plano conceitual quanto nas estratégias de ação. A próxima seção discute este processo com maior profundidade.

\section{A emergência de novas ideias}

\section{sob um novo regime de acumulação de capital}

Para Jessop (2002), as dimensões que sustentavam o KWNS sofreram modificações no decorrer da crise econômica abrindo caminho para críticas e principalmente para sua reformulação em novas bases. Cabe ressaltar fatores que minaram o KWNS: as 
contradições inerentes ao modelo, o avanço da globalização e, juntamente com o item anterior, o processo de abertura dos mercados nacionais para a competição internacional. No primeiro caso, destaca-se a rigidez espacial do processo produtivo fordista, que se restringia basicamente à escala nacional, o que favorecia o poder de barganha dos sindicatos, comprometendo, com isso, as taxas de lucro dos capitalistas. Com isso houve redução dos níveis de investimento e, consequentemente do emprego, levando a uma elevação nos gastos sociais, em especial aqueles direcionados ao custeio dos desempregados. As condições externas também agravaram as finanças dos países, comprometendo ainda mais a efetividade das políticas keynesianas: os dois choques do petróleo durante os anos de 1970, em conjunto com a iniciativa do governo norte-americano de elevar a taxa de juros já no final desta década, aumentaram ainda mais o endividamento desses países.

Quanto à dimensão relativa à função do Estado em garantir a reprodução da força de trabalho, Jessop (2002) mostra que a identificação, por parte dos teóricos neoliberais, de que os gastos sociais geram ineficiências alocativas, produziu transformações na essência das políticas sociais: elas não seriam mais concebidas como instrumento necessário ao incremento da demanda agregada dos países, nem muito menos enquanto garantia de coesão social, mas sim como custo econômico/financeiro que deveria ser controlado em virtude dos constantes desequilíbrios das contas públicas. O avanço das políticas neoliberais objetivou produzir, dessa forma, um descolamento das políticas econômicas em relação às políticas sociais, onde a lógica das primeiras passou a controlar tanto a concepção, quando as formas de atuação das segundas. Como exemplo, o salário social que prevaleceu no KWNS como uma das formas de garantir a expansão da demanda agregada via consumo coletivo - não mais apenas dos trabalhadores, mas também de suas famílias - passou a ser considerado como custo de produção, o que levou o Estado capitalista a implementar a flexibilização da legislação trabalhista em uma série de países, com o objetivo de garantir maior competitividade internacional às empresas.

Jessop (2002), no entanto, não aponta para a tendência de redução ou desaparecimento das políticas sociais, já que seu papel continua sendo fundamental no processo de reprodução da força de trabalho. Ao seguir a linha proposta por Gough (1979), ele observa uma reformulação da natureza delas, que não mais corresponderia aos objetivos políticos, econômicos e sociais do modelo de desenvolvimento Pós-Segunda Guerra Mundial. De forma diferente, as políticas sociais seriam concebidas com o objetivo de viabilizar os ganhos das empresas capitalistas, ficando o bem-estar social em segundo plano. Em suma, a reprodução da força de trabalho estaria garantida, mas as motivações que estiveram na origem da formação dos 
welfare States no Pós-Segunda Guerra Mundial - como os direitos sociais, a busca pela coesão social e o desenvolvimento econômico em suas múltiplas dimensões - foram substituídas por motivações de natureza produtivista, onde as políticas sociais beneficiariam especialmente aqueles indivíduos que estivessem no mercado de trabalho.

Estas transformações estariam relacionadas à formação de um novo modo de regulação, no qual a forma e a função institucional do Estado estariam cristalizadas no tipo-ideal chamado de Schumpeterian workfare postnational regime, o que representa mudanças significativas em relação ao antigo modo de regulação. Para sintetizar a discussão, a substituição do termo keynesian por schumpeterian deve-se à prioridade conferida pelo Estado à elaboração de políticas pelo lado da oferta, garantindo, com isso, condições de competitividade às empresas no mercado cada vez mais globalizado. O termo workfare substitui o welfare, pois as políticas sociais adquirem uma lógica produtivista, ou seja, questões como direitos sociais e cidadania, que estavam na origem da formação do regime de welfare State, se enfraqueceram, cedendo espaço para questões relacionadas à competitividade e redução nos custos de produção, que formariam a base para a elaboração de políticas sociais que teriam como objetivo inserir um número cada vez maior de indivíduos no mercado de trabalho. Com isso, as políticas sociais ganhariam uma conotação de welfare to work, ou seja, os trabalhadores teriam acesso a determinados benefícios sociais que são negados àqueles que não fazem parte do mercado de trabalho, deixando esses últimos com acesso restrito e reduzido aos benefícios, o que, em muitos casos, tenderia a gerar sua estigmatização. Fazem parte ainda da forma institucional cristalizada no workfare a flexibilização dos direitos trabalhistas, o incremento de políticas focadas e residuais (means-tested) e o fortalecimento de políticas voltadas para o desenvolvimento das capacidades dos indivíduos, como as de educação, de forma a prepará-los para entrarem no mercado de trabalho futuro.

O termo postnational em substituição a national deve-se à ampliação das fronteiras de atuação das empresas que, devido à introdução de inovações tecnológicas, ganharam maior mobilidade espacial, podendo deslocar-se para outras localidades - seja dentro do próprio país, seja para outros países - onde os custos de produção sejam menores. Por fim, a introdução do termo regime em substituição ao State ocorre em virtude da existência de novos mecanismos de governança que não se restringem apenas aos Estados. Cabe ressaltar, nesse sentido, a adoção de mecanismos de governança política e social, parcerias entre empresas, entre Estados e empresas, bem como entre Estado e sociedade civil, além de redes de trabalho (networked) (Jessop, 1999). 
O Schumpeterian workfare postnational regime forneceu as bases para a consolidação de um novo regime de acumulação, cuja natureza pós-fordista deslocou o eixo de acumulação do capital, que se voltou para a expansão das condições de oferta da economia - seja de trabalho ou de bens e serviços. O processo de legitimação deste novo modo de regulação contou ainda com a incorporação de "novas ideias" ao arcabouço de políticas econômicas e sociais, que passaram a se articular dentro de uma nova lógica - fundamentada por uma nova visão de mundo - fornecendo as bases teóricas para a reestruturação das políticas sociais.

Neste sentido, merece destaque o conjunto de ideias que fazem parte do arcabouço analítico desenvolvido pela terceira via, que promoveu uma redefinição de conceitos centrais à proteção social, como cidadania, bem-estar e exclusão social, cujo sentido passou a estar relacionado à inserção da população no mercado de trabaIho. Seus adeptos sugerem o fim da dicotomia entre mercado e Estado, apontando para a articulação de ambos na promoção do desenvolvimento econômico, tendo o Estado a responsabilidade de fortalecimento das relações mercantis nos países. As políticas sociais teriam como objetivo garantir o bem-estar dos indivíduos, que seriam beneficiados através da capacitação e da concessão de incentivos pecuniários para que eles tenham acesso ao mercado de trabalho (Giddens, 1999).

Autonomia e individualização também fazem parte do framework do social risk management, conjunto de ideias e recomendações de políticas disseminadas pelo Banco Mundial a partir do início dos anos 2000. Ao defenderem a focalização das políticas sociais nos segmentos mais pobres da população - como forma de combate à vulnerabilidade social, que ocorreria através de políticas residuais de transferências de renda -, seus defensores se posicionam claramente pela subordinação das políticas sociais às políticas econômicas ortodoxas, voltadas para o controle dos gastos públicos (Holzmann \& Jørgensen, 2000). Numa releitura do monetarismo implementado no início dos anos 1980, o social risk management defende a remercantilização da reprodução das condições de vida da população, o que significa, em outras palavras, tornar os indivíduos vulneráveis às instabilidades oriundas das flutuações cíclicas da economia.

Como exemplo da importância destas ideias para a instituição do novo paradigma de políticas sociais, cabe destacar a reestruturação das políticas de transferência de renda do Reino Unido, que ganharam centralidade na estratégia de desenvolvimento do governo do novo trabalhismo (1997-2011), tendo, por isso, passado por transformações significativas, que implicaram mudanças em seus objetivos. A principal dessas transformações se refere à natureza destas políticas que, baseada 
numa concepção de cidadania distinta da que perdurou no período Pós-Segunda Guerra Mundial, passou a condicionar o acesso a um grande número de benefícios pecuniários à participação dos indivíduos no mercado de trabalho. Calcadas nas ideias da terceira via, as políticas de transferências monetárias britânicas passaram a ter um objetivo que iria além do fornecimento de condições básicas de subsistência para a população, passando a operar como instrumento de estímulo à expansão da oferta de trabalho na economia.

\section{Efeitos das ideias da terceira via sobre as políticas de transferência de renda no governo do novo trabalhismo}

As ideias contidas na terceira via propiciaram, como forma de garantir a participação de toda a população no processo de desenvolvimento econômico, os elementos que permitiram a criação de elos que articulassem as políticas desenvolvidas no campo econômico com as políticas sociais. Para tanto, defendia a mobilização ativa de todas as instituições econômicas e sociais - como o mercado, o Estado, as comunidades e instituições voluntárias - como forma de garantir a inclusão de todos os indivíduos no processo de produção capitalista, o que na, visão de Anthony Giddens (1999), seu principal teórico, era condição fundamental para a obtenção da igualdade social. De acordo com o referido autor, a terceira via pode ser caracterizada a partir de três pilares que, juntos, forneceriam as bases explicativas para as mudanças nos princípios que regem a sociedade britânica: o pilar da governança, o da promoção do bem-estar social e o da cidadania.

O pilar da governança se refere às formas de articulação entre Estado e mercado e seus efeitos sobre a criação de oportunidades para que os indivíduos possam desenvolver ao máximo suas capacidades individuais, de forma a torná-los independentes das redes assistenciais do Estado. Dessa forma, Giddens (1999) defende que a dicotomia entre Estado e mercado deveria ser substituída por uma sinergia entre ambos, onde o dinamismo do mercado seria canalizado para a obtenção do interesse público. Em outras palavras, a globalização teria uma conotação positiva, caso seus frutos fossem canalizados para o bem-estar da sociedade, o que seria alcançado através da regulação - não coerção - do mercado pelo Estado, ou seja, a ideia de mercado autorregulável é criticada, dando espaço a uma visão do mercado como lócus de criação de oportunidades, o que seria feito em parceria com o Estado.

O segundo pilar relaciona-se à promoção do bem-estar social, que deveria ser garantido exclusivamente por meio da participação de todos os indivíduos - aptos 
- no mercado de trabalho. Neste sentido, Giddens (1999) defende a criação de um welfare positivo, ou seja, um sistema de proteção social que, ao invés de apenas proteger os indivíduos contra a ineficiência de uma economia de mercado, contribui para que eles se tornem mais independentes e aptos a lidarem com as transformações no mundo do trabalho. Com isso, a criação de oportunidades estaria no cerne das políticas de bem-estar social defendidas pela terceira via, o que significa uma rejeição às políticas que mantêm os indivíduos dependentes de benefícios concedidos pelo Estado. Para tanto, as políticas de welfare deveriam focar constantemente no investimento em capital humano, seja na política educacional e de capacitação, seja nas políticas voltadas para a manutenção da renda.

Por fim, o terceiro pilar diz respeito às transformações na concepção de cidadania, a qual passou a estar relacionada a obrigações e condicionalidades, ou seja, os direitos sociais estariam garantidos para aqueles indivíduos que estivessem no mercado de trabalho ou procurando emprego - exceção feita às pessoas incapazes de trabalhar. Em outros termos, a concepção de direitos sociais que estava relacionada à simples condição de pertencimento a uma dada comunidade política (cidadania pelo status) foi substituída por uma cidadania baseada no mérito daqueles indivíduos que estivessem contribuindo para o desenvolvimento da nação. Esta mesma ideia de cidadania pauta o entendimento que os teóricos da terceira via têm em relação à desigualdade, cuja redução dependeria da inclusão, no mercado de trabalho, dos grupos populacionais de maior vulnerabilidade (Glyn \& Wood, 2001). As questões estruturais referentes à reprodução das desigualdades sociais são deixadas em segundo plano, afastando, da mesma forma, os mecanismos não mercantis utilizados para sua redução.

A terceira via redefiniu um conjunto de ideias que forneceu as bases para o processo de reestruturação das políticas sociais britânicas. Ao condicionarem, por exemplo, a obtenção da cidadania à participação de todos os indivíduos no mercado de trabalho, o governo do novo trabalhismo, signatário dessas ideias, propôs uma série de políticas de transferência de renda que beneficiariam mais quem estivesse trabalhando ou procurando emprego em detrimento daqueles que, por algum motivo, estivessem fora do mercado de trabalho. Comandada pelo ministro das Finanças e chanceler Gordon Brown, a mais importante dessas modificações esteve na unificação do sistema tributário (tax credits) com o sistema de benefícios, criando um sistema que favorecia, sobremaneira, mediante incentivos, aquelas pessoas que estivessem trabalhando ou procurando emprego. Procurava-se, com isso, reduzir as armadilhas do desemprego e da pobreza (unemployment and poverty traps), que mantinham os indivíduos fora do mercado de trabalho, já que não precisariam pagar as taxas e os impostos que incidiam sobre quem trabalha. 
4. Esta característica das tax credits tornou-se uma importante aliada na estratégia do governo de manter o orçamento sob controle. De acordo com Glennerster (2007), elas apareciam nas contas nacionais como redução na tributação e não como aumento nos gastos públicos.

5. Os valores das tax credits variam em relação à renda anual do trabalhador. Até uma determinada renda, o trabalhador recebe a totalidade do benefício. A partir de um determinado valor, esse benefício é reduzido progressivamente até cessar. Embora se assemelhe a um sistema de deduções tributárias, a tax credit não paga valores proporcionais ao imposto pago pelo trabalhador. Esse valor é definido de acordo com as diferentes faixas de renda.

6. De acordo com Barr (2004), o papel das tax credits - mais especificamente, as working tax credits - era, ao mesmo tempo, combater a pobreza e aumentar a participação da força de trabalho britânica. Em linhas gerais, o sistema concedia benefícios com base nas faixas de rendimento, mas condicionava a concessão dos mesmos a um número mínimo de horas de trabalho
Este novo sistema concedia benefícios proporcionais à renda anual recebida pelos trabalhadores ao longo do $a_{n o}^{4}$, na forma de tax credits $^{5}$, o que era um incentivo para que os indivíduos se mantivessem no mercado de trabalho, ou procurando emprego, já que a concessão da maior parte dos benefícios estava condicionada a estes dois fatores ${ }^{6}$.

Para tanto, contavam com uma série de mecanismos de incentivo e coerção que estimulavam a procura por trabalho. Em primeiro lugar, aqueles que estavam no mercado de trabalho "eram premiados" com mais benefícios do que os que dele não participavam. Em segundo, o auxílio desemprego seria concedido desde que os trabalhadores desempregados participassem de programas de requalificação, ao mesmo tempo em que se mantivessem procurando trabalho. No caso dos jovens desempregados, especificamente, foram introduzidas quatro opções: trabalho subsidiado, ou seja, o governo daria incentivos a empresas para contratar trabalhadores jovens desempregados; apenas treinamento e qualificação; trabalho voltado para o meio ambiente; e trabalho voluntário (Fraser, 2009).

Posteriormente, foram implementados programas para absorção de outros estratos populacionais pelo mercado de trabalho, como pais solteiros (lone parents), pessoas "incapazes", idosos, principalmente aqueles que acabaram de se aposentar, por falta de trabalho, além daqueles que não estavam à procura de emprego. A ideia era, ao mesmo tempo, expandir a oferta de trabalho e criar oportunidades para que os indivíduos se tornassem independentes dos benefícios sociais tradicionais, recebendo, por outro lado, incentivos para que permanecessem trabalhando ou procurando emprego. Esta dinâmica evidenciava a centralidade que o novo welfare State havia adquirido no âmbito do governo do novo trabalhismo, sendo importantes, para isso, mudanças em sua concepção, o que permite o estreitamento dos laços entre as políticas econômicas e sociais.

Além disso, a ideia de que a igualdade e o bem-estar social são atingidos pelo acesso a oportunidades no mercado de trabalho deslocou a discussão sobre o combate à pobreza do campo redistributivo, colocando-a no âmbito das deficiências de acesso ao mercado laboral. Em outras palavras, a estratégia para a redução da pobreza ao longo das gestões do novo trabalhismo passou pela criação de políticas e benefícios que estimulassem a procura por trabalho, especialmente nas famílias com crianças, que passaram a receber benefícios - do tipo tax credit - para que se mantivessem no mercado de trabalho. Como o foco na redução da pobreza infantil era uma das principais metas do novo trabalhismo, o governo procurou contraí-la através da criação de oportunidades para que os responsáveis por menores tivessem condições de sustentá-las através dos ganhos laborais. 


\section{Considerações finais}

A principal consequência da introdução do novo paradigma de políticas sociais foi o rompimento com a noção - historicamente construída - de proteção social e sua ressignificação a partir de novos pressupostos, cuja natureza é contraditória com as ideias originais que lhe conferiram existência. A adequação de sua forma e do discurso pró-social às plataformas de governos conservadores e mesmo de governos ditos progressistas transparece na manutenção de estratégias de proteção social, traduzidas não apenas em programas e políticas, como também na mobilização crescente dos gastos sociais. Sua natureza, por outro lado, mudou trazendo novos problemas e prioridades à agenda de políticas, constituída a partir de uma nova visão a respeito de seu funcionamento, que passa a girar em torno do fortalecimento das relações mercantis por toda a sociedade. Conceitos como autonomia, competitividade, eficiência e individualização passaram a fundamentar as políticas de proteção social recentes, colocando os indivíduos como principais responsáveis por seu próprio bem-estar e o mercado como o lócus para sua conquista (Simões, 2014; Lavinas \& Simões, 2015).

Sem levar em consideração que o mercado é gerador de profundas desigualdades sociais - que se reproduzem como barreiras de acesso aos serviços essenciais à reprodução das condições de vida da população -, abre-se mão de políticas ex-ante, universais e equalizadoras de oportunidades, priorizando as políticas de inserção dos indivíduos no mercado de trabalho como condição para a obtenção de uma renda que proporcionará o acesso deles a tais serviços. Para aqueles que não possuem emprego, as políticas de transferência de renda permitem que eles tenham acesso ao mercado de consumo que inclui, cada vez mais, serviços sociais voltados aos segmentos mais vulneráveis da população. A provisão de bem-estar social pelo mercado guarda como resultado não apenas a manutenção dos níveis elevados de desigualdade e a exposição da população aos riscos oriundos dos ciclos econômicos, como viabiliza a expansão do processo de acumulação de capital que passa a incorporar os segmentos mais pobres da população à sua lógica.

Cabe ressaltar que a difusão de recomendações de políticas sociais pelas agências multilaterais de desenvolvimento tem seguido esse caminho, tendo sempre um "verniz" de preocupação com a garantia de mínimos sociais para a população, mas sem deixar de vincular suas condições básicas de reprodução à esfera mercantil (Holzmann \& Jørgensen, 2000). A crença na soberania dos mercados sobre a vida dos indivíduos vem se legitimando a partir da disseminação de relatórios destas instituições que, posteriormente, se traduzem em políticas públicas incorporadas às agendas dos países. A articulação destas recomendações com os interesses do
(Barr, 2004). As características do sistema de benefícios ao longo do governo do novo trabalhismo serão aprofundadas na análise setorial das políticas de transferência de renda. 
grande capital é sutil, mas pode ser descortinada em pontos estratégicos, como, por exemplo, na constante presença de representantes do mercado financeiro em diretorias de instituições como o Fundo Monetário Internacional (FMI) e o Banco Mundial, bem como na convergência dos argumentos relativos à necessidade de controle de gastos sociais como fundamento para a reestruturação dos sistemas de proteção sociais.

Este cenário tem como resultado básico a conjugação de uma série de discursos, capitaneados pelos organismos multilaterais, legitimadores do novo paradigma de políticas, que defendem as políticas sociais como condição garantidora da reprodução das condições de vida da população com prática que envolve o desenho de políticas cujo principal objetivo é o aprofundamento das relações mercantis por todos os meandros da sociedade. Isto requer, necessariamente, que o acesso da população à proteção social ocorra, cada vez mais, pelo mercado de consumo. A projeção dessa tendência para o futuro sugere um aumento da vulnerabilidade social em decorrência da instabilidade dos mercados, como também do incremento dos níveis de desigualdade social, não apenas à desigualdade de rendimento - como nos mostrou Piketty (2014) -, mas especialmente pela desigualdade de acesso da população à proteção social.

\section{Referências}

BARR, Nicholas. The economics of the Welfare State. 4th ed. Oxford (UK): Oxford University Press, 2004.

FRASER, Derek. The evolution of the British Welfare State. New York: Palgrave MacMillan, 2009.

GIDDENS, Anthony. A Terceira Via: reflexões sobre o impasse político atual e o futura da social-democracia. Rio de Janeiro: Record, 1999.

GLENNERSTER, Howard. British social policy: 1945 to the present. Oxford (UK): Blackwell Publishing, 2007.

GLYN, Andrew; WOOD, Stewart. Economic policy under new labour: how social democratic is the Blair government? The Political Quarterly, v. 72, n. 1, p. 50-66, 2001. GOUGH, Ian. The polítical economy of the Welfare State. London: MacMillan, 1979. 
HALL, Peter. Policy paradigms, social learning and the State: the case of economic policy-making in Britain. Madrid: Instituto Juan March de Estudios e Investigaciones; Centro de Estudios Avanzados en Ciencias Sociales, 1990.

HOLZMANN, Robert; ১ ØRGENSEN, Steen. Social risk management: a new conceptual framework for social protection and beyond. Washington: World Bank, February, 2000. Disponível em: <http://siteresources.worldbank.org/SOCIALPROTECTION/Resources/SP-Discussion-papers/Social-Risk-Management-DP/0006.pdf>. Acesso em: 15 Set. 2016.

JESSOP, Bob. The future of the capitalist State. Cambridge (UK): Polity Press, 2002.

- The changing governance of welfare: recent trends in primary functions, scale, and modes of coordination. Social Policy \& Administration, v. 33, n. 4, p.348 -359, Dez. 1999.

JUDT, Tony. Pós-Guerra: uma história da Europa desde 1945. Rio de Janeiro: Objetiva, 2008.

KORNIS, George. A crise do Estado de Bem-Estar: problemas e perspectivas da proteção social. Tese (Doutorado em Medicina Social) - Universidade Federal do Rio de Janeiro, 1994.

KORPI, Walter. Economic growth and the Welfare State: leaky bucket or irrigation system? European Sociological Review, v. 1, n. 2, p. 97-118, Sep. 1985.

KUHN, Thomas. A estrutura das revoluções científicas. Rio de Janeiro: Perspectiva, 2010.

LAVINAS, Lena; SIMÕES, André. Social policy and structural heterogeneity in Latin America: the turning point of the 21st Century. In: FRITZ, Barbara; LAVINAS, Lena (Orgs.). A moment of equality for Latin America? Challenges for redistribution. Surrey (UK): Ashgate, 2015.

—_. 21stCentury Welfare. New Left Review, v. 84, p. 5-40, Nov./Dec. 2013.

LINDERT, P. H. Growing public - social spending and economic growth since the Eighteen Century, v. I: "The story". Cambridge: Cambridge University Press, 2004.

MARSHALL, T. H. Cidadania, classe social e status, cap. 3: "Cidadania e classe social", p. 57-114. Rio de Janeiro: Zahar Editores, 1967.

PIKETTY, Thomas. O capital no século XXI. São Paulo: Intrínseca, 2014. 
PIERSON, P. The new politics of the Welfare State. World Politics, n. 48, p. 143-179, Jan. 1996.

POLANYI, Karl. A grande transformação: as origens da nossa época. Rio de Janeiro: Campus, 2000.

SINGH, A. Historical examination of the golden age of full employment in Western Europe. Munich Personal REpEc, 2008, 20p. Disponível em: <https://mpra.ub.uni-muenchen.de/24304/1/Historical_Examination_of_the_Golden_Age_pdf $>$. Acesso em: 25 Mar. 2019.

SIMÕES, André. As políticas sociais no governo do Novo Trabalhismo: algumas reflexões para o Brasil. Revista Política Social e Desenvolvimento, Ano II, p. 25-30, 2014.

WORLD BANK. World development report 2000/1: attacking poverty. Set. 1999. Disponível em: <http://siteresources.worldbank.org/INTPOVERTY/Resources/WDR/ approutl.pdf>. Acesso em: 21 Set. 2016.

. World development report 2000/1: poverty. Jun. 1990. Disponível em: <http://www.rrojasdatabank.info/wdr90/wdr901-13.pdf>. Acesso em: 21 Set. 2016. 